\title{
Fluid therapy and the use of albumin in the treatment of severe traumatic brain injury
}

\author{
M. Rodling Wahlström ${ }^{1}$, M. Olivecrona ${ }^{2}$, F. Nyström ${ }^{1}$, L.-O. D. Koskinen ${ }^{2}$ and S. Naredi ${ }^{1}$ \\ Departments of ${ }^{1}$ Anesthesia and Intensive Care and ${ }^{2}$ Neurosurgery, Umea University Hospital, Umea, Sweden
}

Background: Evidence-based guidelines for severe traumatic brain injury (TBI) do not include strategies for fluid administration. The protocol used in this study includes albumin administration to maintain normal colloid osmotic pressure and advocates a neutral to slightly negative fluid balance. The aim of this study was to analyze the occurrence of organ failure and the mortality in patients with severe TBI treated by a protocol that includes defined strategies for fluid therapy.

Methods: Ninety-three patients with severe TBI and Glasgow Coma Score $\leq 8$ were included during 1998-2001. Medical records of the first 10 days were retrieved. Organ dysfunction was evaluated with the Sequential Organ Failure Assessment (SOFA) score. Mortality was assessed after 10 and 28 days, 6 and 18 months.

Results: The total fluid balance was positive on days 1-3, and negative on days $4-10$. The crystalloid balance was negative from day 2 . The mean serum albumin was $38 \pm 6 \mathrm{~g} / \mathrm{l}$. Colloids constituted $40-60 \%$ of the total fluids given per day. Furosemide was administered to $94 \%$ of all patients. Severe organ failure defined as SOFA $\geq 3$ was evident only for respiratory failure, which was observed in $29 \%$. None developed renal failure. After 28 days, mortality was $11 \%$ and, after 18 months, it was $14 \%$.

Conclusions: A protocol including albumin administration in combination with a neutral to a slightly negative fluid balance was associated with low mortality in patients with severe TBI in spite of a relatively high frequency $(29 \%)$ of respiratory failure, assessed with the SOFA score.

Accepted for publication 13 August 2008

(C) 2008 The Authors

Journal compilation (C) 2008 The Acta Anaesthesiologica Scandinavica Foundation
A DEFINED strategy for volume replacement and fluid balance that includes maintenance of normovolemia and colloid osmotic pressure in combination with a neutral to a slightly negative fluid balance is a cornerstone of the intracranial pressure (ICP)-targeted therapy for severe traumatic brain injury (TBI) used in this study. Colloid osmotic pressure is mainly maintained by hyperoncotic albumin substitution. Diuretics are frequently used. ${ }^{1-6}$ Neither the American Guidelines 2007 nor the European brain injury consortium guidelines for treatment of TBI suggest any strategies for fluid management. ${ }^{7,8}$

Although there is no general agreement on which fluids should be used in critically ill patients, in general intensive care medicine, there exists an increased interest in how fluid replacement and vasopressor drugs may influence non-neurological organ failure and outcome. ${ }^{9-16}$ There are few studies published on TBI with special reference to fluid therapy. ${ }^{6,9,17}$ Concerning the use of albumin in severe TBI, a post hoc analysis of the Saline vs.
Albumin Fluid Evaluation (SAFE) study in patients with severe TBI reported a significantly higher mortality rate in patients assigned to albumin compared with those assigned to saline. ${ }^{17}$

Acute lung injury (ALI) and acute respiratory distress syndrome (ARDS) are reported commonly after TBI and their appearance is associated with fluid management. ALI and ARDS are considered as independent factors for mortality. ${ }^{18-20}$

The aim of this study was to investigate the occurrence of organ failure and mortality in patients with TBI treated according to an ICP-targeted therapy that includes defined strategies for fluid treatment, including albumin administration.

\section{Materials and methods}

\section{Protocol}

The Regional Research Ethics Committee of Umeå, Sweden, approved this study. All patients were treated according to an ICP-targeted therapy based 
on the physiological principles of the Lund concept, thoroughly described in several publications. ${ }^{1-6}$ Colloid osmotic pressure and normovolemia were aggressively maintained mainly with administration of albumin and red blood cells (RBC). Vasopressor active drugs were not part of the protocol and were avoided if possible. Hypotension was treated primarily by volume resuscitation. The fluid balance was kept neutral to slightly negative with diuretics (furosemide).

ICP monitoring was mandatory, ICP was kept $<20 \mathrm{mmHg}$, cerebral perfusion pressure (CPP) $>50 \mathrm{mmHg}$ and mean arterial pressure (MAP) around $70 \mathrm{mmHg}$. Respiratory goals were normoventilation with a $\mathrm{PaCO}_{2}$ of $4.5-5.5 \mathrm{kPa}$ and a $\mathrm{PaO}_{2} \geq 12 \mathrm{kPa}$. Hyperthermia (above $38^{\circ} \mathrm{C}$ ) was avoided. Goals set for laboratory parameters were glucose $3-8 \mathrm{mmol} / \mathrm{l}$, hemoglobin $(\mathrm{Hb}) \geq 110 \mathrm{~g} / \mathrm{l}$, albumin $\geq 40 \mathrm{~g} / \mathrm{l}$ and sodium $135-150 \mathrm{mmol} / \mathrm{l}$.

\section{Patients}

The 93 patients were admitted to the Umeå University Hospital from January 1998 to December 2001. The Umeå University Hospital has the regional responsibility of an area of $225,464 \mathrm{~km}^{2}$ with a population of about 0.9 million. Inclusion criteria were age of 15-70 years, blunt head trauma, Glasgow Coma Score (GCS) $\leq 8$ by the time of sedation and intubation, arrival at the Intensive Care Unit (ICU) within $24 \mathrm{~h}$ after the accident and $\mathrm{CPP} \geq 10 \mathrm{mmHg}$ when introducing the ICP monitor. Patients who could be discharged from the ICU alive within $72 \mathrm{~h}$ after admittance were not included even if they fulfilled above the inclusion criteria. Patients who died within $72 \mathrm{~h}$ after admittance and patients with GCS 3 and non-reactive dilated pupils with intention to treat at admittance were included.

\section{Monitoring}

All patients had ICP monitored with an intraparenchymal Codman MicroSensor ${ }^{\mathrm{TM}}$ (Johnson \& Johnson Professional Inc., Raynham, MA), calibrated according to the manufacture's instructions, and/ or ventriculostomy. The zero-pressure baseline for the ventriculostomy was set at the pre-auricular level with the patient in the supine position with no head elevation. Systemic blood pressure was invasively measured with the zero-pressure baseline set at the heart level.

\section{Data collection}

Physiological data were collected from the time of arrival at the ICU and until removal of the ICP monitor. Laboratory data were recorded daily and arterial blood gases were recorded at least every $8 \mathrm{~h}$ in all patients. Computed tomography (CT) of the brain and chest $X$-rays were performed at admission and thereafter whenever clinically indicated.

\section{Fluids}

Recorded fluids given (colloids and crystalloids), recorded fluids lost (urinary output, perspiratio, bleeding and drainage fluids), drugs administered and laboratory values were assessed for each patient. The total fluid balance was calculated using a computerized standard setup (CareSuit ${ }^{\circledR}$ Critical Care Manager, Picis Inc. Wakefield, MA). The protocol requires that weight should be checked every second day. In this study, bodyweight was initially estimated and then the accurate weight was confirmed within 2-7 days. Colloids refer to solutions with molecular weight $>30 \mathrm{kDa}$ and crystalloids to solutions with molecular weight $<30 \mathrm{kDa}$. The colloids used were hyperoncotic $20 \%$ albumin, $4 \%$ albumin, plasma and packed RBC. No synthetic colloids were used. The crystalloids used were Ringer acetate and Saline $0.9 \%$. For fluid balance calculations, drug infusions and nutritional fluids were included in crystalloids. The amount of enteral feeding depended on the status of the bowel function; 0-1500 $\mathrm{ml}$ /day was administered with a step-wise daily increase, 300-500-1000-1500 ml/day. As nutritional fluids, the patients were given glucose solutions $(2.5-20 \%)$ with electrolytes added, in combination with enteral feeding and/or parenteral nutrition.

\section{Scoring}

All the patients were scored by GCS, Acute Physiologic and Chronic Health Evaluation II (APACHE II) and Injury Severity Score (ISS). ${ }^{21}$ Severe injury was defined as ISS $\geq 16$. Organ failure was scored by Sequential Organ Failure Assessment (SOFA). ${ }^{22}$ The worst registered parameter per day was scored from 0 to 4, without consideration of the duration of the worst value noticed. Severe organ failure was defined as SOFA $\geq 3$. Because of sedation, the central nervous system was not evaluated.

The criteria according to the American-European Consensus Conference (EACC) were used for ARDS and ALI evaluation. The EACC criteria 
used were acute onset, $\mathrm{PaO}_{2} / \mathrm{FiO}_{2} \leq 300 \mathrm{mmHg}$ $(40 \mathrm{kPa})$ for ALI and for ARDS $\mathrm{PaO}_{2} /$ $\mathrm{FiO}_{2} \leq 200 \mathrm{mmHg}(26 \mathrm{kPa})$, bilateral infiltration at frontal chest $\mathrm{X}$-ray and absence of clinical evidence of left atrial hypertension. ${ }^{23}$ The Glasgow Outcome Score (GOS) was scored by independent research staff. Mortality was assessed at 10 and 28 days, 6 and 18 months after trauma.

\section{Statistical analyses}

Data are presented as mean \pm standard deviation, percentage (\%) or median (range). The level of significance was $P \leq 0.05$. The non-parametric Mann-Whitney $U$-test was used for non-normal distribution. The $\chi^{2}$-test was used for nominal data. SPSS 12.0 for Windows (SPSS, Chicago, IL) and Excel $\left(\right.$ Microsoft ${ }^{\mathcal{O}}$ ) were used for statistical analyses.

\section{Results}

\section{Study population}

The study included 93 patients with TBI mostly due to motor-vehicle accidents. The features of the study population and the physiological parameters during the first $24 \mathrm{~h}$ are given in Table 1. All patients had pathological findings at the initial CT scan of the brain. Surgery for non-neurosurgical injuries was performed in 26\% (24/93) and neurosurgery in $70 \%$ of the patients (65/93). In addition to the TBI, $42 \%$ of the patients were classified as multiple traumas. Thoracic injuries were observed in $16 \%$ (15/93). Non-survivors (28-day mortality) were more severely traumatized with statistically significantly higher APACHE II and ISS scores $(P \leq 0.05)$ and a statistically significantly lower GCS score $(P \leq 0.05)$ compared with survivors. (Table 1)

\section{Pharmacy}

Diuretics were given to $94 \%$ (87/93) and vasopressor drugs were administered to $45 \%$ of the patients (42/93) during the first 10 days of ICU care. Vasopressor support was most abundant during day 2 when it was administered to $28 \%$ of the patients (26/93). Diuretics were most abundant on day 3, to $70 \%(65 / 93)$ of the patients. Vasopressor support was rarely used after day 6. (Fig. 1) Prostacyclin (epoprostenol, Flolan ${ }^{\circledR}$; GlaxoSmithKline, Uxbridge, UK) was used in this study for all patients as a complement to the protocol in order to improve cerebral microcirculation. ${ }^{24,25}$
Table 1

Features of study population of the first $24 \mathrm{~h}$ at the ICU.

\begin{tabular}{|c|c|c|c|}
\hline & $\begin{array}{l}\text { Total } \\
\text { study } \\
(n=93)\end{array}$ & $\begin{array}{l}\text { Survivors } \\
(n=83)\end{array}$ & $\begin{array}{l}\text { Non- } \\
\text { survivors } \\
(n=10)\end{array}$ \\
\hline \multicolumn{4}{|l|}{ Demographics } \\
\hline Age (years) & $37.6 \pm 16.1$ & $37.0 \pm 16.1$ & $42.1 \pm 16.8$ \\
\hline Gender M/F (\%) & $76 / 24$ & $74 / 26$ & $90 / 10$ \\
\hline APACHE & $19(9-27)$ & $18(9-26)$ & $25(17-27)^{\star}$ \\
\hline ISS & $18(9-43)$ & $17(9-41)$ & $35(16-43)^{*}$ \\
\hline GCS & $7(3-8)$ & $7(3-8)$ & $3(3-7)^{*}$ \\
\hline Multitrauma (\%) & 42 & 42 & 40 \\
\hline \multicolumn{4}{|c|}{ Physiological parameters } \\
\hline $\begin{array}{l}\text { Maximum ICP } \\
(\mathrm{mmHg})\end{array}$ & $24 \pm 1.2$ & $24 \pm 1.2$ & $29 \pm 5.5$ \\
\hline $\begin{array}{l}\text { Maximum MAP } \\
(\mathrm{mmHq})\end{array}$ & $94 \pm 1.3$ & $94 \pm 1.4$ & $92 \pm 3.9$ \\
\hline $\begin{array}{l}\text { Minimum CPP } \\
(\mathrm{mmHg})\end{array}$ & $53 \pm 11.0$ & $54 \pm 10.0$ & $48 \pm 12.0$ \\
\hline Maximum HR (b.p.m.) & $89 \pm 1.8$ & $88 \pm 1.9$ & $94 \pm 7.1$ \\
\hline CVP $(\mathrm{mmHg})$ & $10 \pm 0.5$ & $10 \pm 0.5$ & $10 \pm 1.5$ \\
\hline Urine $(\mathrm{ml} / \mathrm{kg} / \mathrm{h})$ & $37 \pm 3$ & $38 \pm 4$ & $42 \pm 12$ \\
\hline Albumin $(g / l)$ & $35.0 \pm 0.7$ & $35.9 \pm 0.7$ & $31.3 \pm 2.4$ \\
\hline Sodium (mmol/l) & $141 \pm 0.5$ & $141 \pm 0.6$ & $143 \pm 2.1$ \\
\hline $\mathrm{Hb}(\mathrm{g} / \mathrm{l})$ & $116 \pm 1.4$ & $117 \pm 1.5$ & $109 \pm 4.6$ \\
\hline
\end{tabular}

Total study and subgroups of survivors vs. non-survivors (28day mortality).

$n$ patients, age presents as mean \pm SD.

Statistical significance;

${ }^{\star} P \leq 0.05$, survivors vs. non-survivors.

Type of accident presents in percent. ICP, intracranial pressure; MAP, mean arterial pressure; CPP, cerebral perfusion pressure; $\mathrm{HR}$, heart rate; CVP, central venous pressure; $\mathrm{Hb}$, hemoglobin; data present as mean $\pm S D$.

Mean of maximum ICP per day in each patient.

Mean of minimum CCP per day in each patient.

M, male; F, female; APACHE II, Acute Physiological and Chronic Health Evaluation II; ISS, Injury Severity Score; GCS, Glasgow Coma Scale, data present in percent or median (range); TBI, traumatic brain injury; ICU, Intensive Care Unit.

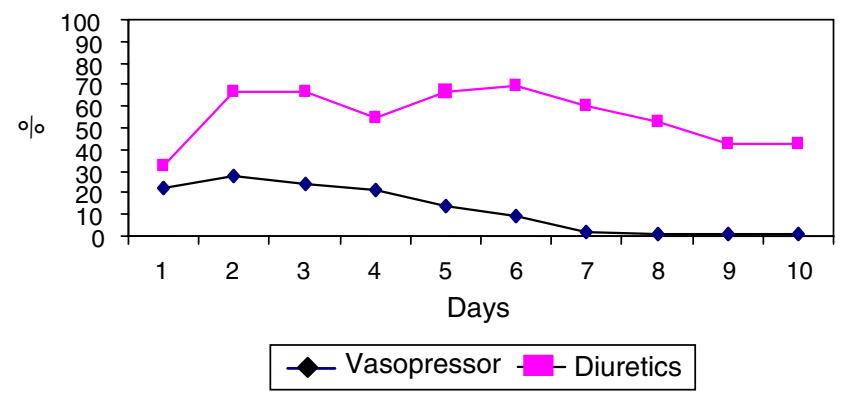

Fig. 1. Administration of vasopressor drugs (phenylephrine and norepinephrine) and diuretic drugs (furosemide) during the first 10 days. Data are presented in percent of patients receiving the drugs per day.

\section{Fluid management}

The mass (gram) and volume (ml) of albumin were calculated because individuals received either 
or both $4 \%$ albumin and hyperoncotic $20 \%$ albumin. The distribution in volume between $4 \%$ albumin and hyperoncotic 20\% albumin was $45 \%$ vs. $55 \%$.

Table 2 describes the total cumulative volume administration days $1-4$ in all patients $(n=91)$, survivors $(n=81)$ and non-survivors $(n=10)$. Data of fluids from two patients were lost due to technical computer problems.

Serum sodium, albumin, $\mathrm{Hb}$ and blood glucose were kept within the limits of the protocol, and no significant differences were found during days 1-4 between survivors and non-survivors. (Table 2)

The total fluid balance and the exclusive crystalloid fluid balance are shown in Fig. 2. The total fluid balance for the patients revealed a positive fluid balance on days $1-3$, and a slightly negative fluid balance on days 4-10. The crystalloid fluid balance showed negative values from day 2 . From day 3, crystalloids were given in amounts of 30 $35 \mathrm{ml} / \mathrm{kg} /$ day. Colloids constituted between $40 \%$ and $60 \%$ of the total fluids given per day. (Fig. 3) Patients were receiving enteral feeding by a nasogastric tube, median $100 \mathrm{ml} /$ day/patient (range 0 $1000 \mathrm{ml}$ ), during the first 4 days.

Physiological parameters were kept within normal ranges for all patients. On days 1-10, the mean MAP was $88 \pm 9 \mathrm{mmHg}$, the mean heart rate was $73 \pm 12$ and the mean central venous pressure was $12 \pm 4 \mathrm{mmHg}$.

\section{Organ failures}

Severe organ failure was defined as SOFA score $\geq 3$ in each organ system. ${ }^{22}$ No patient developed severe renal or circulatory failure. Severe liver or coagulation dysfunctions were observed in one patient, respectively. Respiratory dysfunction was the predominant organ failure; a SOFA score $\geq 3$ for this parameter was observed in $29 \%$ of the patients (27/93) (Table 3). According to the criteria for ARDS and ALI by AECC, 14\% (13/93) developed ARDS and 4\% (4/93) developed ALI.



Fig. 2. Total fluid balance and crystalloid fluid balance days 1-10. $\diamond$, total fluid balance; $\diamond$, only crystalloid fluid balance. Mean $\pm S D$ (ml/kg/patient/day). n, number of patients.

Table 2

Mean of accumulated total volume given and laboratory values days 1-4.

\begin{tabular}{|c|c|c|c|c|c|c|}
\hline & $\begin{array}{l}\text { Total study } \\
(n=93)\end{array}$ & $n$ & $\begin{array}{l}\text { Survivors } \\
(n=83)\end{array}$ & $n$ & $\begin{array}{l}\text { Non-survivors } \\
(n=10)\end{array}$ & $n$ \\
\hline \multicolumn{7}{|l|}{ Volumes } \\
\hline Crystalloids (ml/kg) & $159.9 \pm 55.7$ & 91 & $160.2 \pm 55.9$ & 81 & $158.0 \pm 57.3$ & 10 \\
\hline Albumin $(\mathrm{ml} / \mathrm{kg})$ & $44.9 \pm 34.3$ & 91 & $45.3 \pm 33.7$ & 81 & $41.6 \pm 41.0$ & 10 \\
\hline Packed red blood cells $(\mathrm{ml} / \mathrm{kg})$ & $39.8 \pm 30.8$ & 91 & $37.4 \pm 29.7$ & 81 & $60.0 \pm 33.9$ & $10^{*}$ \\
\hline Plasma $(\mathrm{ml} / \mathrm{kg})$ & $28.5 \pm 21.7$ & 69 & $28.7 \pm 21.8$ & 60 & $27.4 \pm 21.6$ & 9 \\
\hline Colloids (ml/kg) & $106.4 \pm 60.7$ & 91 & $103.9 \pm 61.1$ & 81 & $126.0 \pm 56.8$ & 10 \\
\hline Albumin (g/patient) & $227.0 \pm 107.0$ & 91 & $236.0 \pm 108.0$ & 91 & $160.0 \pm 65.0$ & $10^{\star}$ \\
\hline \multicolumn{7}{|l|}{ Laboratory values } \\
\hline $\mathrm{Hb}(\mathrm{g} / \mathrm{l})$ & $123 \pm 11$ & 93 & $123 \pm 10$ & 83 & $118 \pm 13$ & 10 \\
\hline Sodium/serum (mmol/l) & $143 \pm 6$ & 93 & $142 \pm 5$ & 83 & $146 \pm 6$ & 10 \\
\hline Albumin/serum $(\mathrm{g} / \mathrm{l})$ & $38 \pm 6$ & 93 & $39 \pm 6$ & 83 & $34 \pm 4$ & 10 \\
\hline Blood glucose $(\mathrm{mmol} / \mathrm{l})$ & $7.0 \pm 1.4$ & 93 & $7.0 \pm 1.4$ & 83 & $7.4 \pm 1.1$ & 10 \\
\hline
\end{tabular}

Mean of the total amount of accumulated volumes for each patient per kilo bodyweight during the first $96 \mathrm{~h}$ of Intensive Care Unit (ICU) cares (days 1-4)

Total study group and subgroups of survivors vs. non-survivors (28-day mortality).

All data are presented as mean \pm SD.

Statistical significance;

${ }^{\star} P \leq 0.02$, survivors vs. non-survivors.

$n=$ patients. 


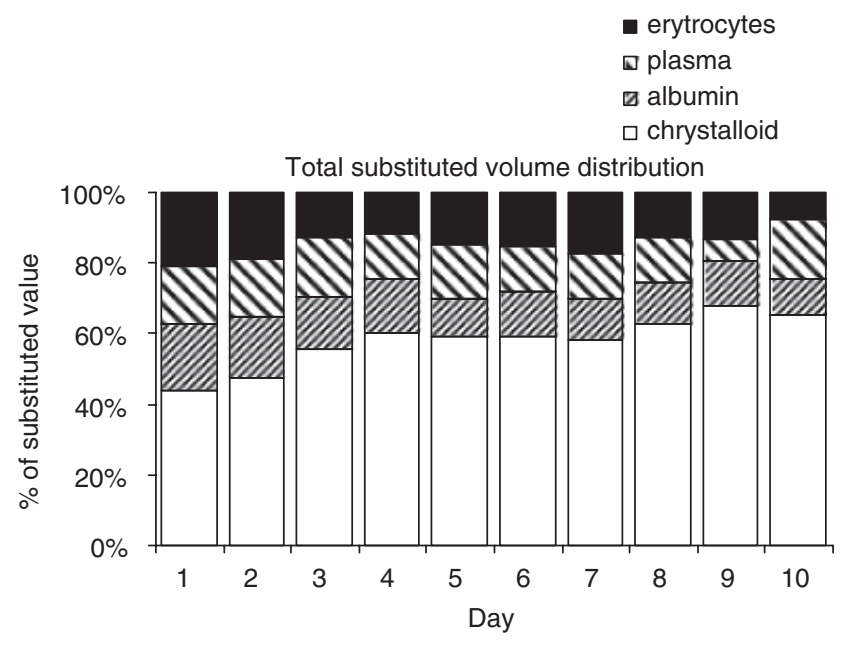

Fig.3. Total volume distribution. Volumes given separated into crystalloids, albumin, packed red blood cells and plasma. Data are given in percent of total volume per day.

Table 3

\begin{tabular}{|c|c|c|c|}
\hline \multicolumn{4}{|l|}{ SOFA score. } \\
\hline \multirow[t]{2}{*}{ SOFA score } & \multicolumn{3}{|c|}{ All patients } \\
\hline & $=2$ & $=3$ & $=4$ \\
\hline Renal & $0.1 \%$ & - & - \\
\hline Circulatory & $13 \%$ & - & - \\
\hline Coagulopathy & $20 \%$ & $0.7 \%$ & - \\
\hline Liver & $26 \%$ & $1 \%$ & - \\
\hline Respiratory & $36 \%$ & $25 \%$ & $4 \%$ \\
\hline
\end{tabular}

Recorded frequency of organ failure according to SOFA score, days $1-10$.

Data are presented in percent of all patients.

SOFA, Sequential Organ Failure Assessment.

\section{Outcome}

Mortality was 5\% (5/93) after 10 days, 11\% (10/93) after 28 days, $13 \%$ (12/93) by 6 months and $14 \%$ (13/93) after 18 months.

GOS was recorded more than 6 months after injury. The median GOS was 4 (1-5). Good recovery, GOS 5, was confirmed in $40 \%$ (37/92). The favorable outcome group, GOS 4-5 (moderate disability / good recovery), was 63\% (58/92) and the unfavorable outcome group, GOS 1-3 (death/vegetativedisabled), was $37 \%$ (34/92). One patient was lost to follow-up. Simple correlation analysis showed no statistical significance between GOS and albumin, either given as volume (ml) or mass $(\mathrm{g})$.

\section{Discussion}

This study confirms that patients with TBI, treated with albumin after head injury, do not have excess mortality compared with other cohorts described. ${ }^{11,19,26-28}$ The outcome data in this study are in accordance with other published studies on patients with TBI treated according to the Lund concept. ${ }^{1-6}$ This ICP-targeted therapy has a defined strategy for volume replacement and fluid balance. The treatment protocol emphasizes the maintenance of normovolemia and colloid osmotic pressure in combination with a neutral to slightly negative fluid balance in order to avoid interstitial edema.

There are few studies regarding fluid therapy in TBI and the evidence-based American guidelines do not contain any fluid strategies. ${ }^{7}$ The SAFE study in mixed ICU patients suggested a harmful effect of albumin in patients with TBI. ${ }^{9}$ A post hoc follow-up study in patients with severe TBI reported a significantly higher mortality rate in patients assigned to albumin (28 days 34\%, 6 months 39\%) than among those assigned to saline (28 days 19\%, 6 months $22 \%$ ). ${ }^{17,29}$

In spite of albumin administration, the mortality rate of $11 \%$ at 28 days and $13 \%$ after 6 months in this study is lower than for both the albumin and the saline group in the SAFE-TBI study. ${ }^{17,29}$

Albumin administration in the critically ill has been debated intensively since the publication of the meta-analysis from the Cochrane group in 1998. ${ }^{10}$ Albumin was stopped at many ICUs around the world at that time, even though a new meta-analysis, with more studies included, could not confirm an adverse effect of albumin on mortality. ${ }^{30}$ In a recently published randomized study on albumin administration in the critically ill (TBI patients excluded), hyperoncotic $20 \%$ albumin was reported to improve organ function as assessed by a SOFA score. ${ }^{31}$ An expected effect of administration of hyperoncotic albumin would be fluid mobilization from the interstitial space and an increase in intravascular volume. Some experimental and clinical studies support the view that a high plasma oncotic pressure reduces ICP by limiting transcapillary fluid filtration into the brain parenchyma across a damaged blood-brain barrier. ${ }^{32-35}$

In a recently published clinical study, hypoalbuminemia was a possible independent predictor of an unfavorable outcome in patients with severe TBI. ${ }^{27}$ Hypoproteinemia is correlated to fluid retention, weight gain and development of ARDS. ${ }^{15}$ In an experimental study, Powers et al. ${ }^{13}$ showed that resuscitation with 25\% albumin significantly reduced transpulmonary protein flux. In a clinical trial, Martin et al. ${ }^{12}$ reported that the combination 
of albumin and furosemide significantly improved oxygenation in patients with ARDS/ALI. In our study, both $4 \%$ albumin and hyperoncotic $20 \%$ albumin were used, but there was a predominance for hyperoncotic $20 \%$ albumin. Ninety-four percent of our patients received furosemide in combination with albumin administration.

Albumin possesses additional biological properties, other than to maintain the colloid osmotic pressure that could be of importance in critically ill patients. Human albumin is a free radical scavenger and could also be involved in the regulation of neutrophil activation. ${ }^{36}$ Non-neurological organ dysfunction in the absence of systemic injury is common in patients with TBI. The most frequent organ dysfunction reported is respiratory failure, followed by cardiovascular failure. ${ }^{37}$ An occurrence of ARDS/ALI between $10 \%$ and $30 \%$ has been reported in patients with TBI without systemic injuries and is considered an important factor for morbidity and mortality in such patients. ${ }^{11,19,20}$ In our study, we observed severe respiratory failure $(\mathrm{SOFA} \geq 3)$ in $29 \%$ of all patients and an ARDS/ ALI incidence of $18 \%$. Notwithstanding this observation, the mortality rate was low.

In a randomized-controlled study, it was discovered that a CPP-targeted therapy for treatment of TBI was associated with a higher incidence of ARDS, probably due to the extensive use of fluids and vasopressor drugs. ${ }^{11}$ In CPP-targeted therapies, there may be a conflict between treatment strategies for intracranial hypertension and ARDS/ALI. ${ }^{11,20}$ The ICP-targeted therapy used in this study with maintenance of the oncotic pressure with albumin can have effects by preventing both cerebral edema and ARDS/ALI development. ${ }^{12,13,31,32}$

Extensive use of vasopressor has been associated with the development of ARDS/ALI. ${ }^{11}$ In our study, during the first 4 days of ICU care, more than $70 \%$ of the patients per day did not require any vasopressor support. According to the protocol, vasopressor should be avoided. The use of vasopressor is usually due to difficulties in achieving normovolemia in the early phase.

The total fluid balance was positive on days 1-3 and negative on day 4 . The crystalloid balance was negative from day 2. From days 3 to 10, crystalloids were administered for the basal need of water only. This indicates that the patients did not receive a large cumulative free water volume load with the risk of developing interstitial edema. Even though glucose infusions (sodium and potassium always added) were used as nutritional fluids, the low mortality rate in this study does not indicate adverse effects due to free water flux caused by glucose infusions. We keep the glucose levels close to normal all the time with administration of insulin intravenously.

Other than the risk of transfusion-induced ALI, transfusions of RBC may depress immune function and increase the risk of infection. ${ }^{38}$ In this study, the $\mathrm{Hb}$ level was kept within normal limits, the mortality rate was low and the incidence of ARDS/ ALI was not increased compared with other TBI cohort studies. This does not support that TBI patients should always be transfused to a normal $\mathrm{Hb}$ level but major adverse effects were not obvious. Recently published studies have reported increased local cerebral oxygenation after RBC transfusions. ${ }^{39,40}$ Perhaps new transfusion indicators such as brain tissue oxygen partial pressure, rather than the $\mathrm{Hb}$ level are needed for TBI patients.

The results from this study, with a positive total fluid balance within the first 4 days in combination with a favorable outcome after TBI, are in accordance with the results from the NABISH: $\mathrm{H}$ hypothermia study. ${ }^{41}$

One study limitation is the absence of an early initial weight of the patient at arrival after trauma, which is difficult to obtain in a clinical setting. The fluid balance is always counted on the closest recorded bodyweight per patient per day according to our computer system. Another study limitation is that albumin administration and neutral fluid balance are not the only treatment strategies in our treatment protocol. But albumin transfusion in this setting is not associated with excess mortality in patients with severe TBI compared with other cohorts described. On the contrary, in spite of albumin administration, the mortality rate is among the lowest reported in patients with severe TBI.

The treatment protocol used in this study is largely in accordance with the American guidelines for severe TBI, except for strategies concerning fluid management, where no guidelines exist.7 Perhaps the time has come to specifically study the effects of different fluid management approaches in a large randomized study.

\section{Conclusion}

This ICP-targeted treatment protocol with a defined strategy for volume substitution and fluid balance, including maintenance of normal colloid 
osmotic pressure mainly with administration of albumin, was not associated with excess mortality in patients with severe TBI, even though $29 \%$ of the patients had severe respiratory failure assessed by SOFA (SOFA $\geq 3$ ).

\section{Acknowledgements}

This study was financially supported by the Faculty of Medicine, Umeå University, Sweden, and the Västerbotten Country Council, Sweden.

\section{References}

1. Eker C, Asgeirsson B, Grände PO, Schalén W, Nordström $\mathrm{CH}$. Improved outcome after severe head injury with a new therapy based on principles for brain volume regulation and preserved microcirculation. Crit Care Med 1998; 26: 1881-6.

2. Naredi S, Eden E, Zäll S, Stephensen H, Rydenhag B. A standardized neurosurgical/neurointensive therapy directed toward vasogenic oedema after severe traumatic brain injury: clinical results. Intensive Care Med 1998; 24: 446-51.

3. Wahlstrom MR, Olivecrona M, Koskinen LOD, Rydenhag B, Naredi S. Severe traumatic brain injury in paediatric patients: treatment and outcome using an intracranial pressure targeted therapy - the Lund concept. Intensive Care Med 2005; 31: 832-9.

4. Olivecrona M, Wahlstrom MR, Naredi S, Koskinen LOD. Effective ICP reduction by decompressive craniectomy in patients with severe traumatic brain injury treated by an ICP-targeted therapy. J Neurotrauma 2007; 6: 927-35.

5. Asgeirsson B, Grände PO, Nordström CH. A new therapy of post-trauma brain oedema based on haemodynamic principles for brain volume regulation. Intensive Care Med 1994; 20: 260-7.

6. Grände PO. The "Lund concept" for treatment of severe brain trauma- physiological and clinical application. Review. Intensive Care Med 2006; 34: 2456-62.

7. The Brain Trauma Foundation; The American Association of Neurological Surgeons; Congress of Neurological Surgeons. Guidelines for the management of severe traumatic brain injury. J Neurotrauma 2007; 24 (Suppl. 1): S1-106.

8. Stocchetti N, Penny KI, Dearden M, Braakman R, Cohadon F, Iannotti F, Lapierre F, Karimi A, Maas A Jr, Murray GD, Ohman J, Persson L, Servadei F, Teasdale GM, Trojanowski $\mathrm{T}$, Unterberg AEuropean Brain Injury Consortium. Intensive care management of head-injured patients in Europe: a survey from the European brain injury consortium. Intensive Care Med 2001; 27: 400-6.

9. The SAFE Study investigators; Australian and New Zealand Intensive Care Society Clinical Trials Group; Australian Red Cross Blood Service; George Institute for International HealthFinfer S, Bellomo R, Boyce N, French J, Myburgh J, Norton R. A comparison of albumin and saline for fluid resuscitation in the intensive care unit. N Engl J Med 2004; 350: 2247-56.

10. Cochrane Injuries Group Albumin Reviewers. Human albumin administration in critically ill patients: systematic review of randomised controlled trials. BMJ 1998; 317: 235-40.

11. Robertson CS, Valdaka AB, Hannay HJ, Contant CF, Gopinath SP, Cormio M, Uzura M, Grossman RG. Prevention of secondary ischemic insults after severe head injury. Crit Care Med 1999; 27: 2086-95.

12. Martin GS, Moss M, Wheeler AP, Mealer M, Morris JA, Bernard GR. A randomized, controlled trail of furosemide with or without albumin in hypoproteinemic patients with acute lung injury. Crit Care Med 2005; 33: 1681-7.

13. Powers K, Kapus A, Khadaroo RG, He R, Marshall JC, Lindsay TF, Rotstein OD Twenty-five percent albumin prevents lung injury following shock/resuscitation. Crit Care Med 2003; 31: 2355-63.

14. Vincent JL, Navickis RJ, Wilkes MM. Morbidity in hospitalized patients receiving human albumin: a meta-analysis of randomized, controlled trails. Crit Care Med 2004; 32: 2029-38.

15. Mangialardi RJ, Martin GS, Bernard GR, Wheeler AP, Christman BW, Dupont WD, Higgins SB, Swindell BB. Hypoproteinemia predicts acute respiratory distress syndrome development, weight, gain, and death in patients with sepsis. Crit Care Med 2000; 28: 3137-45.

16. Abid O, Akca S, Haji-Michael P, Vincent JL. Strong vasopressor support may be futile in the intensive care unit patient with multiple organ failure. Crit Care Med 2000; 28: 947-9.

17. SAFE Study investigators; Australian and New Zealand Intensive Care Society Clinical Trials Group; Australian Red Cross Blood Service; George Institute for International HealthMyburgh J, Cooper DJ, Finfer S, Bellomo R, Norton R, Bishop N, Kai Lo S, Vallance S. Saline or albumin for fluid resuscitation in patients with traumatic brain injury. N Engl J Med 2007; 357: 874-84.

18. Bratton SL, Davis RL. Acute lung injury in isolated traumatic brain injury. Neurosurgery 1997; 40: 707-12.

19. Holland MC, Mackersie RC, Morabito D, Campell AR, Kivett VA, Patel R, Erickson VR, Pittet JF. The development of acute lung injury is associated with worse neurologic outcome in patients with severe traumatic brain injury. J Trauma 2003; 55: 106-11.

20. Contant CF, Valdaka AB, Gopinath SP, Hannay HJ, Robertson CS. Adult respiratory distress syndrome: a complication of induced hypertension after severe head injury. J Neurosurg 2001; 95: 560-8.

21. Greenspan L, Mclellan BA, Greig H. Abbreviated Injury Scale and Injury Severity Score: a scoring chart. J Trauma 1985; 25: 60-4.

22. Vincent JL, Moreno R, Takala J, Willatts S, De Mendoca A, Bruining H, Reinhart CK, Suter PM, Thijs LG. The SOFA (Sepsis-Related Organ Failure Assessment) score to describe organ dysfunction/failure. Intensive Care Med 1996; 22: 707-10.

23. Bernard GR, Artigas A, Brigham KL, Carlet J, Falke K, Hudson L, Lamy M, Legall JR, Morris A, Spragg R. The American-European Consensus Conference on ARDS. Definitions, mechanisms, relevant outcomes, and clinical trail coordination. Am J Respir Crit Care Med 1994; 149 (3, Part1): 818-24.

24. Grände PO, Möller AD, Nordström CH, Ungerstedt U. Low-dose prostacyclin in treatment of severe brain trauma evaluated with microdialysis and jugular bulb oxygen measurements. Acta Anaesthesiol Scand 2000; 44: 886-94.

25. Naredi S, Olivecrona M, Lindgren C, Östlund AL, Grände PO, Koskinen LOD. An outcome study of severe traumatic head injury using "the Lund therapy" with low-dose prostacyclin. Acta Anaesthesiol Scand 2001; 45: 1-5. 
26. Stocchetti N, Rossi S, Buzzi F, Mattioli C, Paparella A, Colombo A. Intracranial hypertension in head injury: management and results. Intensive Care Med 1999; 25: 371-6.

27. Schirmer-Mikalsen K, Vik A, Gisvold SE, Skandsen T, Hynne H, Klepstad P. Severe head injury: control of physiological variables, organ failure and complications in the intensive care unit. Acta Anaesthesiol Scand 2007; 51: 1194-201.

28. Patel HC, Bouamra O, Woodford M, King AT, Yates DW, Lecky FE. Trends in head injury outcome from 1989 to 2003 and the effect of neurosurgical care; an observational study. Lancet 2005; 366: 1538-44.

29. Grände PO. Time out for albumin or a valuable therapeutic component in severe head injury? Acta Anaesthesiol Scand 2008; 52: 738-41.

30. Wilkes MM, Navicks RJ. Patient survival after human albumin administration. A meta-analysis of randomized controlled trials. Ann Intern Med 2001; 135: 149-64.

31. Dubois MJ, Orellana-Jimenez C, Melot C, De Backer D, Berre J, Leeman M, Brimioulle S, Appolini O, Creteur J, Vincent JL. Albumin administration improves organ function in critically ill hypoalbuminemic patients: a prospective, randomized, controlled, pilot study. Crit Care Med 2006; 34: 2536-40.

32. Zhuang J, Shackford SR, Schmoker JD, Pietropaoli JA Jr. Colloid infusion after brain injury: effect on intracranial pressure, cerebral blood flow, and oxygen delivery. Crit Care Med 1995; 23: 140-8.

33. Drummond JC, Patel PM, Cole DJ, Kelly PJ. The effect of the reduction of colloid reduction of oncotic pressure, with and without reduction of osmolality, on post-traumatic cerebral edema. Anesthesiology 1998; 88: 993-1002.

34. Albright AL, Latchaw RE, Robinson AG. Intracranial and systemic effects of osmotic and oncotic therapy in experimental cerebral edema. J Neurosurg 1984; 60: 481-9.
35. Tomita H, Ito U, Tone O, Masaoka H, Tominaga B. High Colloid oncotic therapy for contusional brain edema. Acta Neurochir Suppl (Wien) 1994; 60: 547-9.

36. Rhee P, Wang D, Ruff P, Austin B, DeBraux S, Wolcott K, Burris D, Ling G, Sun L. Human neutrophil activation and increased adhesion by various resuscitation fluids. Crit Care Med 2000; 28: 74-8.

37. Zygun DA, Kortbeek JB, Fick GH, Laupland KB, Doig CJ. Non-neurological organ dysfunction in severe traumatic brain injury. Crit Care Med 2005; 33: 654-60.

38. Hébert $\mathrm{P}$, Tinmouth $\mathrm{A}$, Corwin $\mathrm{H}$. Controversies in RBC transfusion in the critically ill. Chest 2007; 131: 1583-90.

39. Smith MJ, Stiefel MF, Magge S, Frangos S, Bloom S, Gracias V, Le Roux PD. Packed red blood cell transfusion increases local cerebral oxygenation. Crit Care Med 2005; 33: 1104-8.

40. Leal-Noval SR, Rincón-Ferrari MD, Marin-Niebla A, Cayuela A, Arellano-Orden V, Marín-Caballos A, AmayaVillar R, Ferràndiz-Millón C, Murillo-Cabeza F. Transfusion of erythrocyte concentrates produces a variable increment on cerebral oxygenation in patients with severe traumatic brain injury a preliminary study. Intensive Care Med 2006; 32: 1733-40.

41. Clifton GL, Miller ER, Choi SC, Levin HS. Fluid thresholds and outcome from severe brain injury. Crit Care Med 2002; 30: 739-45.

Address:

Marie R. Wahlström

Department of Anesthesia and Intensive Care

Umeå University Hospital

90185 Umeå

Sweden

e-mail: marie.rodling@anestesi.umu.se 